\title{
IL-32a suppresses colorectal cancer development via TNFR1-mediated death signaling
}

\author{
Hyung-Mun Yun ${ }^{1, *}$, Kyung-Ran Park ${ }^{1, *}$, Eun-Cheol Kim ${ }^{1}$, Sang Bae Han ${ }^{2}$, Do Young \\ Yoon $^{3}$, Jin Tae Hong ${ }^{2}$ \\ ${ }^{1}$ Department of Maxillofacial Tissue Regeneration, School of Dentistry and Research Center for Tooth \& Periodontal \\ Regeneration (MRC), Kyung Hee University, Seoul 130-701, Republic of Korea \\ ${ }^{2}$ College of Pharmacy and Medical Research Center, Chungbuk National University, Heungduk-gu, Cheongju, Chungbuk \\ 361-763, Republic of Korea \\ ${ }^{3}$ Department of Bioscience and Biotechnology, Bio/Molecular Informatics Center, Konkuk University, Seoul 150-716, Republic \\ of Korea \\ *These authors have contributed equally to this work
}

Correspondence to:

Jin Tae Hong, e-mail: jinthong@chungbuk.ac.kr

Keywords: IL-32a, colon cancer, TNFR I, RIPI

Received: January 01, 2015

Accepted: January 25, 2015

Published: April 13, 2015

\section{ABSTRACT \\ Inflammation is associated with cancer-prone microenvironment, leading to cancer. IL-32 is expressed in chronic inflammation-linked human cancers. To investigate IL-32a in inflammation-linked colorectal carcinogenesis, we generated a strain of mice, expressing IL-32 (IL-32a-Tg). In IL-32a-Tg mice, azoxymethane (AOM)-induced colon cancer incidence was decreased, whereas expression of TNFR1 and TNFR1-medicated apoptosis was increased. Also, IL-32a increased ROS production to induce prolonged JNK activation. In colon cancer patients, IL-32a and TNFR1 were increased. These findings indicate that IL-32a suppressed colon cancer development by promoting the death signaling of TNFR1.}

\section{INTRODUCTION}

IL-32 is a novel cytokine, isolated from activated human natural killer (NK) cells or T cells [1-2]. IL-32 $\alpha$ is the shortest over other IL-32 isoforms including IL-32 $\beta$ and IL-32 $\gamma$, which exhibites higher biological activity, inducing cytokines, such as such as Tumour Necrosis Factor- $\alpha($ TNF- $\alpha)$ and macrophage inflammatory protein 2 (MIP-2) [3]. IL-32 $\beta / \gamma$ isoforms were sufficiently detected into cell culture supernatants, whereas IL-32 $\alpha$ was only in intracellular fraction, implying that it has potential roles as non-secreted cytokine although it is considered less potent than other IL-32 isoforms [4-5].

Colorectal cancer (CRC) is a major health problem and frequent cause of cancer mortality in the world [6]. It is the third most commonly diagnosed malignancy and the fourth most common cause of death worldwide [7-8]. The risk of $\mathrm{CRC}$ has been involved in the extent and duration of inflammation [9-10], which is a complex process of molecular and cellular signals, that cells release at the site of the injury to cause a number of changes: increased blood flow, exudation of fluids containing proteins like immunoglobulins, and infiltration by monocytes, granulocytes and lymphocytes. Although individual genetic background is associated with the risk of developing colorectal cancer, the most widely held belief is that the increased cancer risk is chronic inflammation [11]. Supporting evidence is that extensive colitis is a risk factor for CRC [12]. The involvement of inflammatory cytokine IL-32 suggests a potential role in cancer development. In the previous study, we found that IL-32 $\beta$ inhibited melanoma, colon, and prostate cancer growth via the activation of cytotoxic T cells and NK cells [13]. In addition, the overexpression of IL-32 $\beta / \gamma$ may also enhance immune responses to the cancer via an increase of traffic into the cancer area or maturation of immune cells, especially cytotoxic T cells and NK cells [14]. Recently, another study showed that IL-32 $\alpha$ overexpression inhibited human chronic myeloid leukemia via enhancement of NK cells killing ability of natural killer cells [15]. Thus, the present study for IL-32 $\alpha$ in inflammation-linked cancers will present the understanding, the interesting, and the scientific meaning.

Tumor necrosis factor receptor (TNFR) plays a critical role in diverse cellular events, including cell proliferation, 
differentiation, apoptosis, and necrosis [16-17]. Since the discovery of its tumoricidal function that destroys tumor cells, a lot of studies for TNFR signaling have been undertaken [18-19]. The signaling of TNFR is mediated by TNFR1 and TNFR2, resulting in several opposing cellular functions [20-23]. TNFR1 has been shown to promote most often apoptosis, whereas TNFR2 has been shown to be critical in cell migration and proliferation [20-21, 24]. In studies of acute colitis, TNFR1 knockout mice showed development of aggressive dysplastic lesions with more severe inflammation, however, TNFR2 knockout mice did not affect dysplastic changes [24]. The association of TNFR1 with control of apoptosis via death domain-depend signaling, leading to recruiting TNFR1-associated death domoain protein (TRADD), receptor interesting protein 1 (RIP1), TNFR-associated factor 2 (TRAF2), and Fas-associated death domain protein (FADD), and impaired apoptosis is one of hallmarks of carcinogenesis [16, 18, 23, 25].

Many murine models of sporadic and inflammationrelated colon carcinogenesis have been developed in the last decade, including chemically induced CRC [26, 27]. Although inflammation-linked carcinogenesis has been well appreciated, the underlying mechanisms that lead to cancer development in chronic intestinal inflammation remain to be elucidated. In the present study, we investigated whether IL-32 regulates inflammation-linked carcinogenesis using an azoxymethane (AOM)-induced CRC model.

\section{RESULTS}

\section{Inhibition of colon tumor development in IL-32 $\alpha$ transgenic mice}

In order to investigate the functional role of IL-32 $\alpha$ in colon carcinogenesis, we applied a murine colon carcinoma model based on the mutagenic agent, azoxymethan (AOM). 32 weeks after the start of the AOM injections, the mice were sacrificed and monitored. The tumor weight (Figure 1A, ${ }^{*} p<0.5$ ) and volume (Figure $1 \mathrm{~B}, * p<0.5$ ) in IL-32 $\alpha \mathrm{Tg}$ mice were significantly decreased compared with those in non-Tg mice. The immunohistochemical analysis of tissue sections was stained with $\mathrm{H} \& \mathrm{E}$, and proliferating cell nuclear antigen (PCNA) also revealed greater inhibition of tumor growth in IL-32 $\alpha$ Tg mice (Figure 1C). Furthermore, immunohistochemical analysis also showed that numbers of IL-32 $\alpha$ immunoreactive cells were higher in the tissues of IL$32 \alpha \mathrm{Tg}$ mice compared to that in non-Tg mice (Figure 1C).

\section{Upregulation of TNFR1 and induction of cell death in cancer tissue of IL-32 $\alpha$ transgenic mice}

Immunohistochemical staining of colon tumor tissues showed upregulation of TNFR1 expression in IL-32 $\alpha$ Tg mice compared to the tumor tissues in non$\mathrm{Tg}$ mice, while there was no difference of the expression of TNFR2 between non-Tg mice and IL-32 $\alpha$ Tg mice (Figure 2A). Consistent with immunohistochemical staining, the upregulation of TNFRI was also confirmed by Western blot analysis (Figure 2B). TNFR1 primarily initiated cell death pathway, via caspase cleavage. As shown in Figure $2 \mathrm{~B}$ and $2 \mathrm{C}$, the data also showed that the expression of cleaved caspase-8, -9, -3, Bax, and TUNEL-positive cells was increased in the cancer tissues of IL-32 $\alpha \mathrm{Tg}$ mice than in those of non-Tg mice. On the contrary, PCNA, cIAP-1, and XIAP were decreased in tumor tissue lysates from IL-32 $\alpha$ $\mathrm{Tg}$ mice compared to non-Tg mice (Figure 2D). These data suggested that IL-32 $\alpha$ inhibits AOM-induced carcinogenesis by upregulating TNFR1 levels.

\section{IL-32 $\alpha$ inhibits colon cancer cell growth and increases TNFR1-mediated cell death signaling}

Next, it was validated whether IL-32 $\alpha$ inhibits colon cancer cell growth. Consistent with IL-32 $\alpha$ Tg mice, the stable expression of IL-32 $\alpha$ in SW620 cells (SW-IL-32 $\alpha$ cells) was significantly inhibited cell growth in a time dependent manner (Figure 3A). It was also found that SW-IL-32 $\alpha$ cells have higher TNFR1expression level compared to SW-pcDNA cells (Figure 3B). To confirm the promoting effect of IL-32 $\alpha$ on TNFR1-mediated cell death, it was investigated for the expression of apoptotic regulatory proteins in SW-IL-32 $\alpha$ cells. As shown in Figure $3 \mathrm{C}$, in the IL-32 $\alpha$-cells stimulated by TNF- $\alpha$, cleaved caspases- 8 , cleaved caspases- 9 , cleaved caspases-3, and cleaved-Bid were more increased compared to TNF- $\alpha$-stimulated SW-pcDNA cells. Next, it was evaluated for the underlying signal transduction pathway of IL-32 $\alpha$ during TNF- $\alpha$-induced cell growth inhibition. In colon cancer cells, prolonged JNK activation via TNFR1 is involved in growth arrest and cell death. Thus, it was investigated whether the pathways are regulated by IL- $32 \alpha$ in TNF- $\alpha$-mediated cell death. SWIL-32 $\alpha$ cells were treated with TNF- $\alpha$ for $0,1,5,15,30$, and $60 \mathrm{~min}$ and the activation of JNK (phospho-JNK) was measured. TNF- $\alpha$-induced phosphorylation of JNK was significantly increased at $15 \mathrm{~min}$, reached a maximal response at $30 \mathrm{~min}$ and returned to a basal level after 60 min incubation in SW-pcDNA cells. While, in SW-IL$32 \alpha$ cells with TNF- $\alpha$, the activation of JNK (phosphoJNK) was significantly higher, and started to increase significantly at $1 \mathrm{~min}$, reached a maximal response at 30 min, and sustained until $60 \mathrm{~min}$ (Figure 3D). In reverse proportion to JNK activation, it was found that NF- $\kappa \mathrm{B}$ signaling was significantly inhibited in SW-IL-32 $\alpha$ cells (Supplementary Figure 1). These data suggest that IL-32 $\alpha$ enhances TNFR1-mediated cell death signaling.

\section{IL-32 $\alpha$ elevates ROS production to induce prolonged JNK activation}

Sustained JNK activation appears to correlate with ROS generation and cell death. Thus, it was further investigated whether IL-32 $\alpha$ elevated ROS generation 

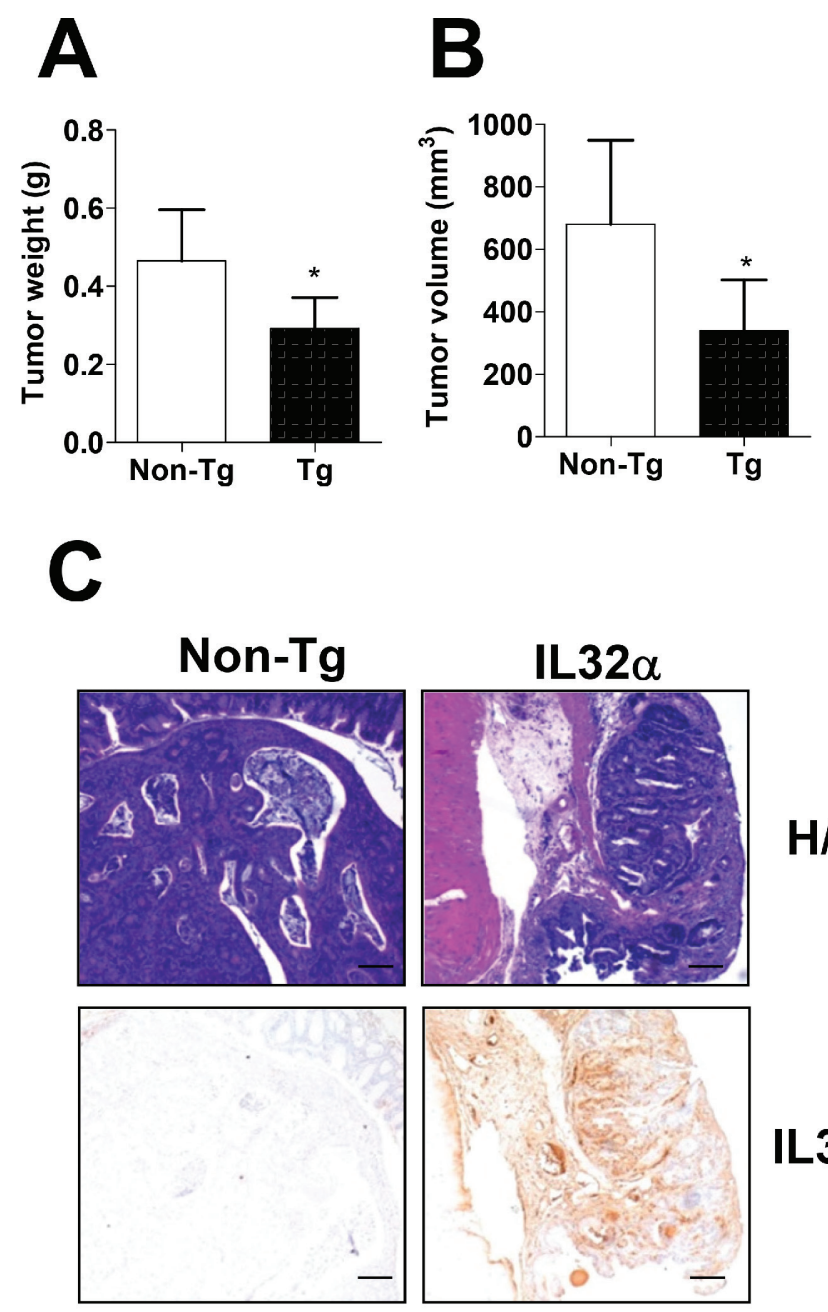

\section{H/E}

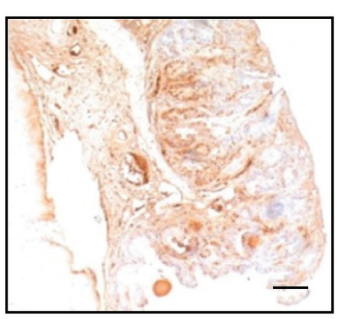

IL32 $\alpha$
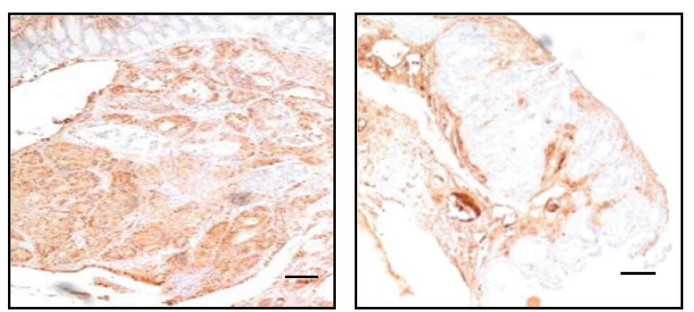

\section{PCNA}

Figure 1: Inhibition of cancer development in IL-32 $\alpha$ Tg mice. (A, B) 7-week-old non-Tg and IL-32 $\alpha$-Tg mice were injected intraperitoneally with $10 \mathrm{mg} / \mathrm{kg}$ of AOM once a week for 6 weeks. Mice were killed at 32 weeks after AOM injections. Colons were harvested and Tumor weight (A) and volume (B) were monitored. (C) Colon tissues were processed and stained with H\&E or analyzed by immunohistochemistry for detection of positive cells for IL-32 $\alpha$ and PCNA. The images are representative of three separate experiments performed in triplicate. Scale bars indicate $100 \mu \mathrm{m}$. *Significant difference from non-Tg mice $\left({ }^{*} p<0.05\right)$.

in colon cancer. As shown in Figure 4, SW-IL-32 $\alpha$ cells significantly increased ROS level (Figure 4A), which was prevented by an inhibitor of nicotinamide adenine dinucleotide phosphate-oxidase (NOX), DPI (Figure 4B). The pretreatment of DPI also inhibited prolonged JNK activation (phospho-JNK) (Figure 4C). It was validated that the knockdown of TNFR1 significantly attenuated ROS generation in SW-IL-32 $\alpha$ cells (Supplementary Figure 2). In parallel with colon cancer cell growth, the phosphorylation of JNK (Figure 4D) and the level of ROS (Figure 4E) were also increased in IL-32 $\alpha$ Tg mice compared to non-Tg mice. These data suggest that ROSJNK signaling of TNFR1 is critical mediator of IL-32 $\alpha$ mediated anti-cancer effect.

\section{Pattern of IL-32 $\alpha$ and TNFR1 expression in human colon cancer}

To further determine the pathological relevance between IL-32 $\alpha$ and TNFR1 expression in colon tumor patients, we examined whether the expression of IL-32 $\alpha$ was related with TNFR1 expression using 
A
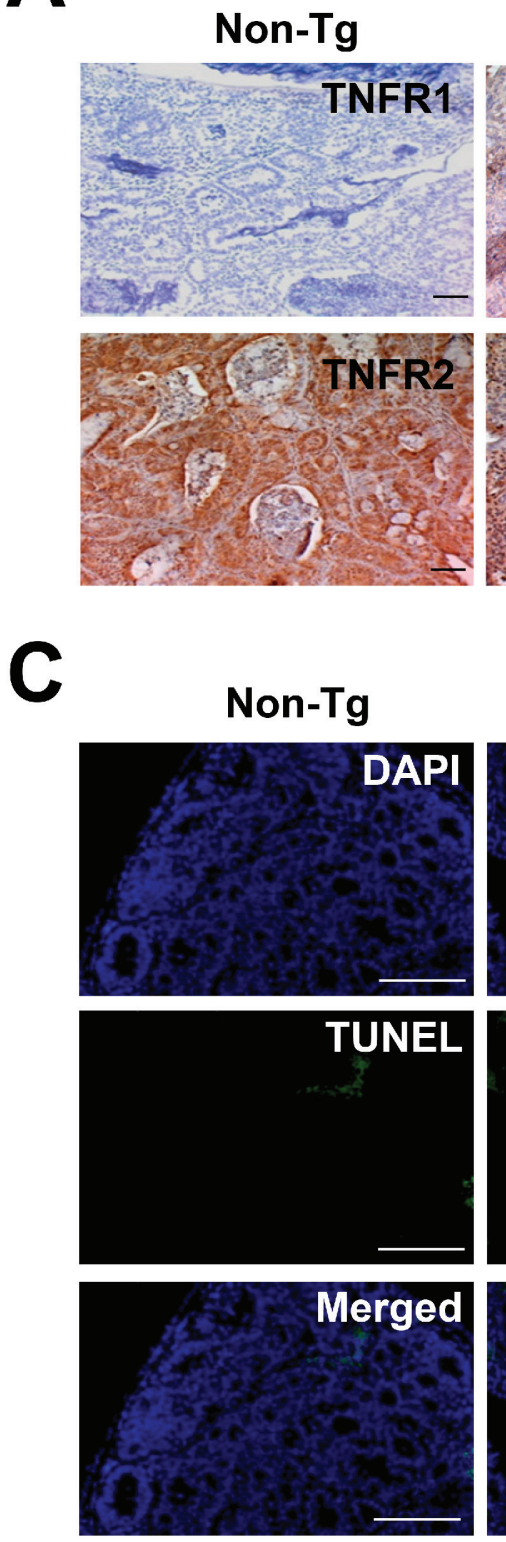
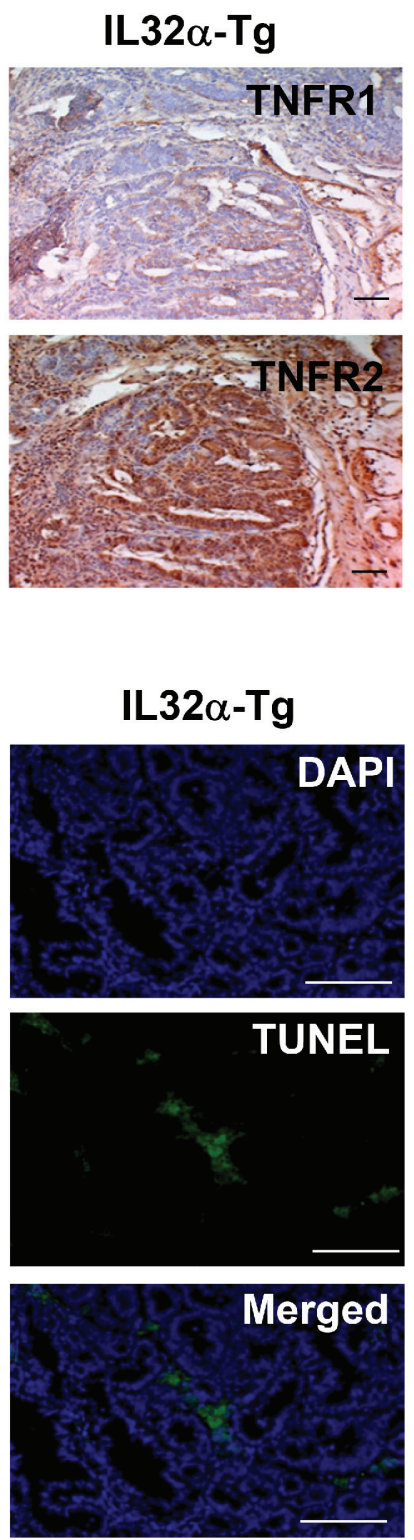

B
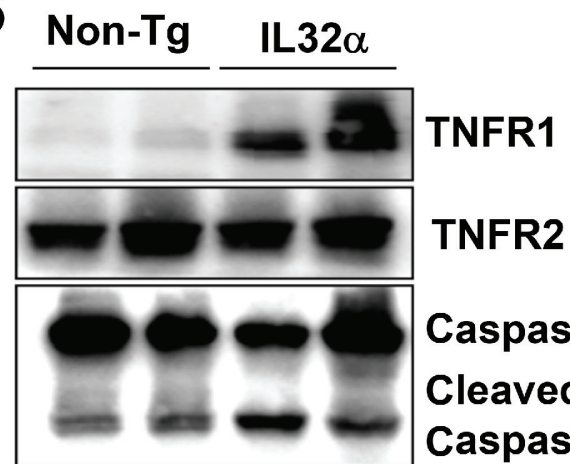

Caspase-

Cleaved

Caspase-

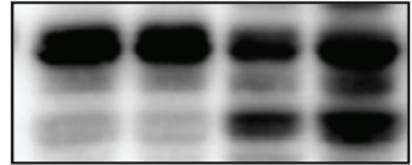

Caspase-

Cleaved

Caspase-

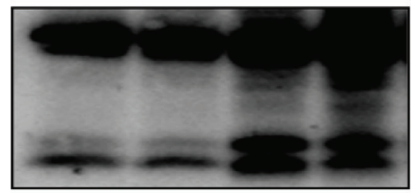

Caspase-3

Cleaved

Caspase-3

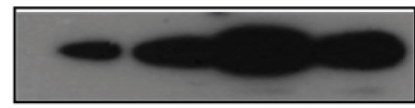

BAX

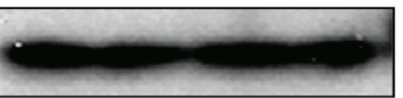

$\beta$-actin

D
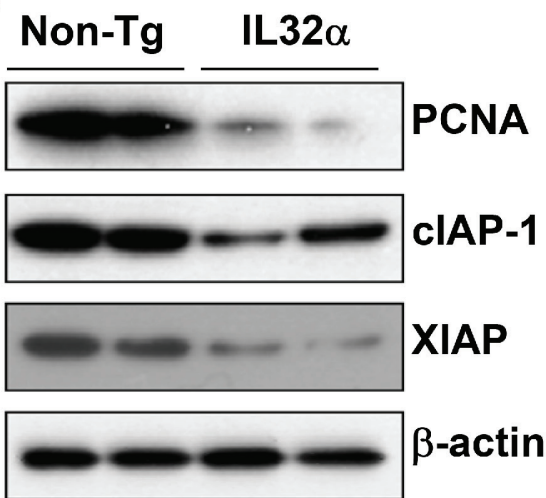

Figure 2: Expression of TNFR1 and cell death in colon cancer tissues of IL-32 $\boldsymbol{\alpha}$ Tg mice. (A) TNFR1 and TNFR2 were observed by immunohistochemical analysis as described in Materials and Methods. (B) The expression of TNFR1, TNFR2, apoptotic proteins were detected by Western blotting using specific antibodies in tumor tissue extracts. $\beta$-actin protein was used as an loading control. (C) Apoptotic cells were examined by TUNEL staining. (D) Cancer extracts were analyzed by Western blotting as described in Materials and Methods section. Each images and band are representative of three independent mice.

application of human colon tumor tissue microarray. In immunohistochemical staining, there was a significant correlation between the IL-32 $\alpha$ and TNFR1 (Figure 5A). Interestingly, IL-32 $\alpha$ and TNFR 1 expression were increased until stage II, whereas the expression was eventually decreased in stage III and IV in human colon tumor tissue when compared to normal colon tissues (Figure 5B and 5C). Thus, these data support the reliability that IL-32 $\alpha$ and TNFR1 may dynamically play a role in the development of human colon cancer.

\section{IL-32 $\alpha$ increases TNFR1-adaptor complex in human colon cancer}

The next question was if IL-32 $\alpha$ was required for a change in the TNFR1-adaptor complex that brings about the binding of the TRADD, TRAF2, and RIP1 adaptor proteins to the death domain of the TNFR1. In SW-IL-32 $\alpha$ cells, TNFR1 led to increased association of a signaling complex including TRADD, RIP1, and TRAF2 compared to SW-pcDNA cells (Figure 6A). In addition, the complex 
A
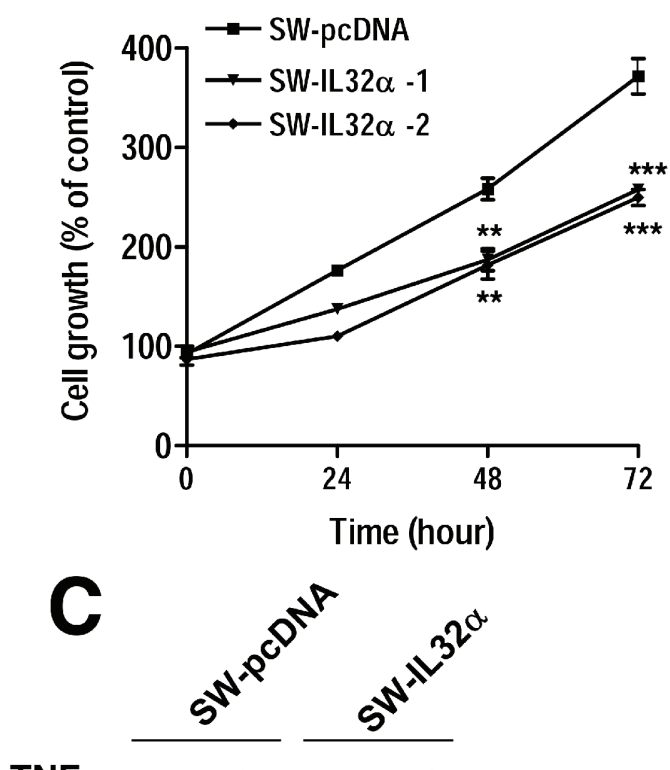

TNF $\alpha:-+\ldots+$

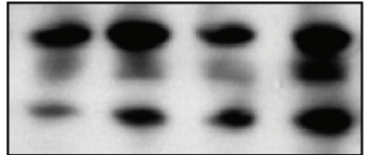

Caspase-8

Cleaved

Caspase-8

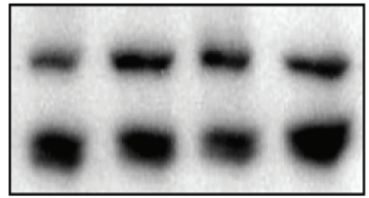

Caspase-9

Cleaved

Caspase-9

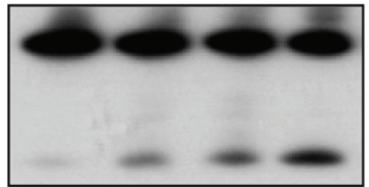

Caspase-3

Cleaved

Caspase-3

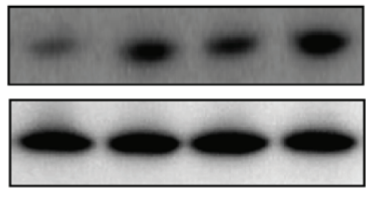

Cleaved-Bid

$\beta$-actin
B

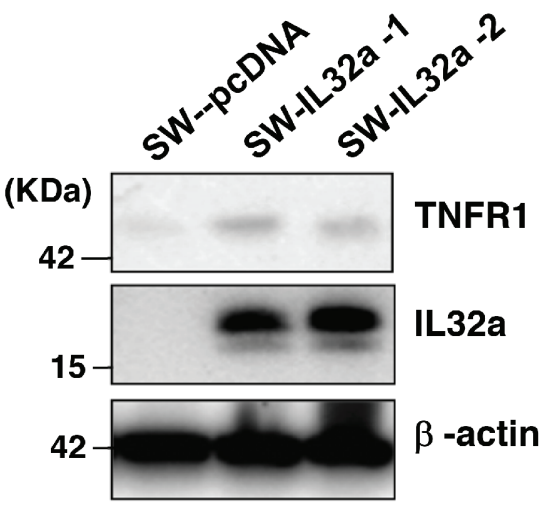

D
SW-IL32 $\alpha$

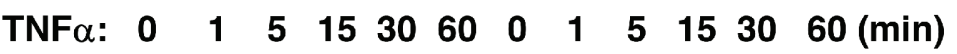
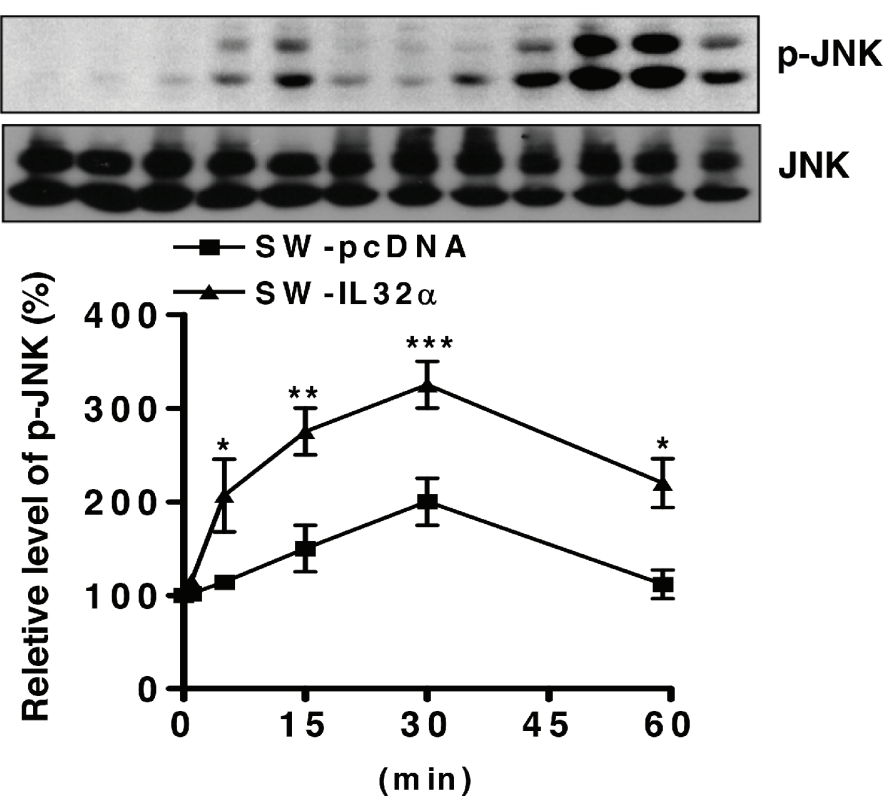

Figure 3: Effects of stable expression of IL-32 $\alpha$ in SW620 cells on colon cancer cell growth and apoptotic signaling. (A) SW620 cells were stably transfected with either the empty pcDNA3.1 vector (SW-pcDNA cells) or the IL-32 $\alpha$ expression vector (SW-IL$32 \alpha$ cells), respectively. Cell growth rate was measured by MTT assay during $72 \mathrm{hr}$ (B) Expression of IL-32 $\alpha$ and TNFR1 is shown by Western blot analysis. $\beta$-actin protein was used as an loading control. (C) Cells were treated with $30 \mathrm{ng} / \mathrm{ml} \mathrm{TNF} \alpha$ for $24 \mathrm{hr}$. Cell extracts were analyzed by Western blotting using specific antibodies. (D) The cells were treated with TNF $\alpha$ ( $30 \mathrm{ng} / \mathrm{ml})$ for the indicated times and assayed to detect phospho-JNK and JNK. The data are represented as relative percentages of the control. *Significant difference from SW-pcDNA cells $(* p<0.05, * * p<0.01$, and $* * * p<0.001)$. Representative results shown in Figure 3 were repeated in triplicate with similar results.

was increased in colon tumor tissues of IL-32 $\alpha \mathrm{Tg}$ mice compared to those of non-Tg mice (Figure 6B). As shown in Figure 6C, the association of TNFR1 with RIP1 was increased until stage II, whereas the association was decreased in stage III and IV in parallel with the expression pattern of IL-32 $\alpha$ and TNFR1 (Figure 5) when compared to normal tissues. Overall our data indicate that
IL-32 $\alpha$ plays a role as a regulator of signaling complex of TNFR1 in the development of human colon tumor.

\section{DISCUSSION}

In present study, we demonstrated that the expression of IL-32 $\alpha$ concomitantly increased the 


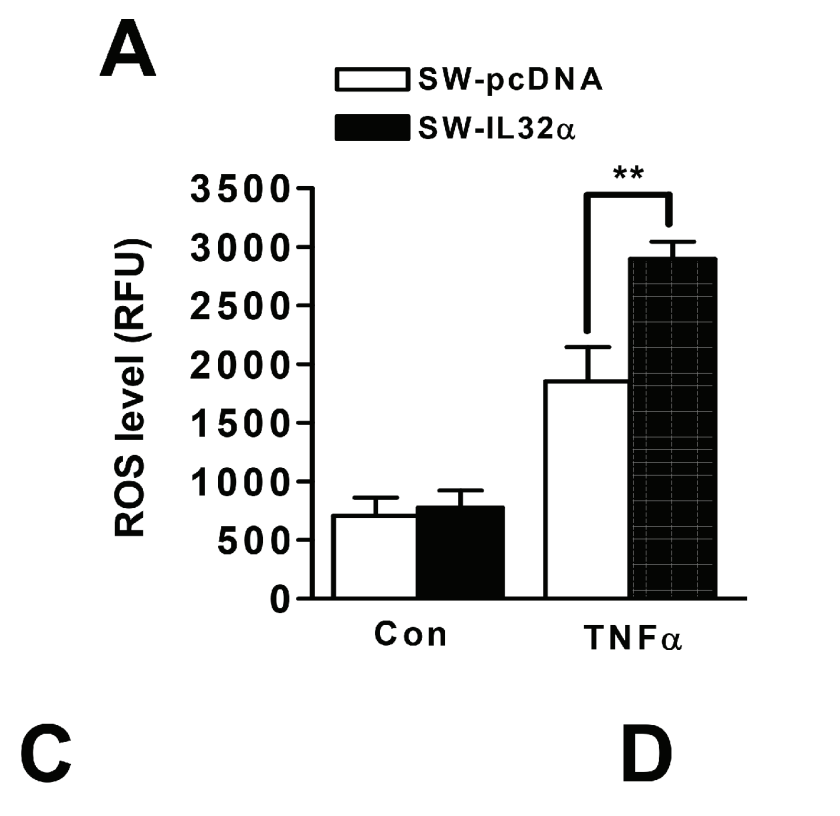

\section{B}
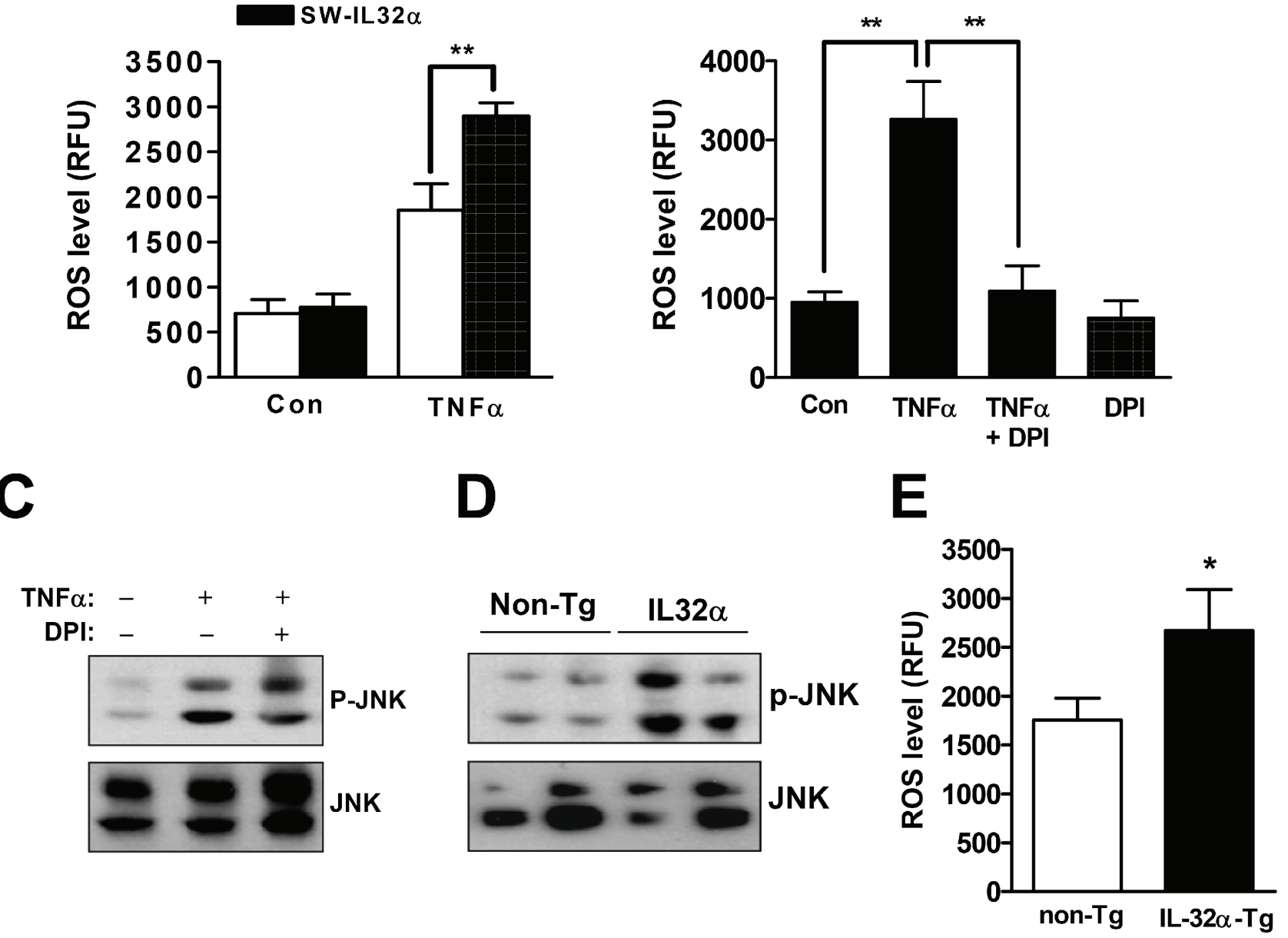

Figure 4: Effects of IL-32 $\alpha$ on ROS release and JNK activation in cancer tissues and colon cancer cells. (A) Cells were treated with $30 \mathrm{ng} / \mathrm{ml} \mathrm{TNF} \alpha$ for $4 \mathrm{hr}$ in SW-pcDNA cells and SW-IL-32 $\alpha$ cells. *Significant difference from SW-pcDNA cells $(* * p<0.01)$. (B) SW-IL-32 $\alpha$ cells were treated with TNF $\alpha$ for $4 \mathrm{hr}$ in the absence or presence of the NOX inhibitor, DPI (20 $\mu \mathrm{M})$ for $30 \mathrm{~min}$. ROS levels were determined using ROS detection kit as described in Materials and Methods section. *Significant difference from control or TNF $\alpha$-treated cell $(* * p<0.01)$. (C) After SW-IL-32 $\alpha$ cells were treated with TNF $\alpha$ for 60 min in the absence or presence of DPI $(20 \mu \mathrm{M})$ for $30 \mathrm{~min}$, cell extracts were analyzed by Western blotting using anti-phospho-JNK and anti-JNK antibodies. (D, E) Cancer extracts were analyzed by Western blotting (D) and ROS detection kit (E) as described in Materials and Methods section. *Significant difference from non-Tg mice $(* * p<0.01)$. Representative results shown in Figure 4 were repeated in triplicate with similar results.

signaling complex of TNFR1 with TRADD, TRAF2, and RIP1 in colon cancer cell, AOM-induced CRC mice, and colon cancer patient tissues. Subsequently, the expression of IL-32 $\alpha$ inhibited colon cancer cell growth and suppressed colorectal cancer development via ROS, JNK, and caspase signaling. TNFR1 has been shown to promote cell death and reduce inflammatory damages [20, 28-29]. The signaling of TNFR1 is initiated by recruitment of cytosolic proteins through protein-protein interaction domains in cytoplasmic death domain which TNFR2 does not contain. TNFR1 recruits a key adaptor protein, TRADD, which serves as a supporting structure for recruitment of TRAF2, RIP-1, FADD, and caspase 8 essential for TNFR1-induced cell death [16, 25, 30]. These data suggest that IL-32 $\alpha$ is closely related to lead to TNFR1-mediated cancer cell death in colorectal cancer development. Previous studies discovered the critical roles of ROS in TNFR1-mediated cell death signaling, in particular on sustained JNK activation [30-32]. It is now recognized that there are two phases of JNK activation mediated by two different activation pathways. The earlier and transient activation of JNK is mediated by TRAF2 [33], whereas the delayed and persistent activation of JNK is mediated by ROS [34-35]. We demonstrated that IL-32 $\alpha$ induced JNK activation and increased ROS production through TNFR1. ROS was also required for JNK activation, which further contributed to ROS production (Supplementary Figure 3). Evidences supporting such notion include that ROS promotes TNFR1-induced sustained JNK activation by inhibiting MAP kinase 


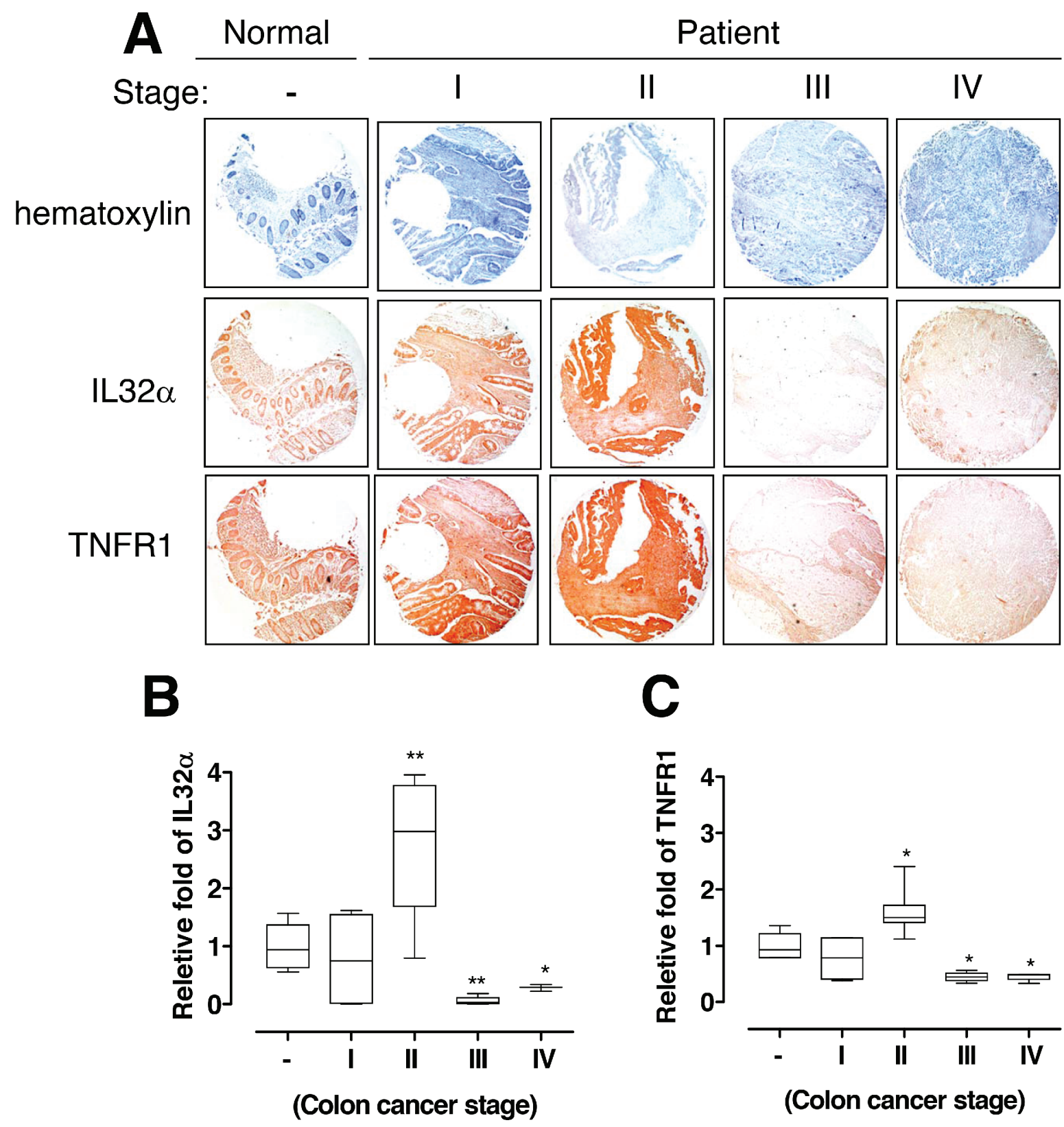

Figure 5: Relationship between IL-32 $\alpha$ and TNFR1 in human colon cancer patients. (A) Human normal colon or cancer sections (Stage I-IV) were processed and stained with Hematoxylin or analyzed by immunohistochemistry for detection of positive cells for IL-32 $\alpha$ and TNFR1. (B, C) The values are releative fold from human normal colon sections against IL-32 $\alpha$ and TNFR1 (C). *Significant difference from normal sections cells $\left({ }^{*} p<0.05\right.$ and $\left.{ }^{* *} p<0.01\right)$.

phosphatases [36] or activating activation of apoptosis signal-regulating kinase 1 (ASK1) that is an upstream protein of JNK and p38, leading to apoptosis (p38 was also activated by IL-32 $\alpha$, Supplementary Figure 4) [3738]. Although it is not known how IL-32 $\alpha$ promotes ROS production, it seems that there is a positive feedback loop between JNK activation and ROS production, and both work together contributing to TNFR1-induced cell death.

The expression of TNFR1 reported prognostic relevance in head and neck cancer (HNC) patients and from patients with other primary carcinomas and sarcomas [39]. Especially, the expression pattern and prognostic impact of TNFR1 in colorectal cancers were reported [40]. Patients with a high TNFR1 expression had a significantly better survival rate than those with a low TNFR1 expression [40]. In the present study, IL$32 \alpha \mathrm{Tg}$ mice showed higher TNFR1 expression in AOMinduced CRC tissues. In human colon tumor patient, the expression pattern of IL-32 $\alpha$ was also correlated with the expression pattern of TNFR1. Interestingly, the expression level was significantly increased until stage II but drastically decreased in stage III/IV. To 


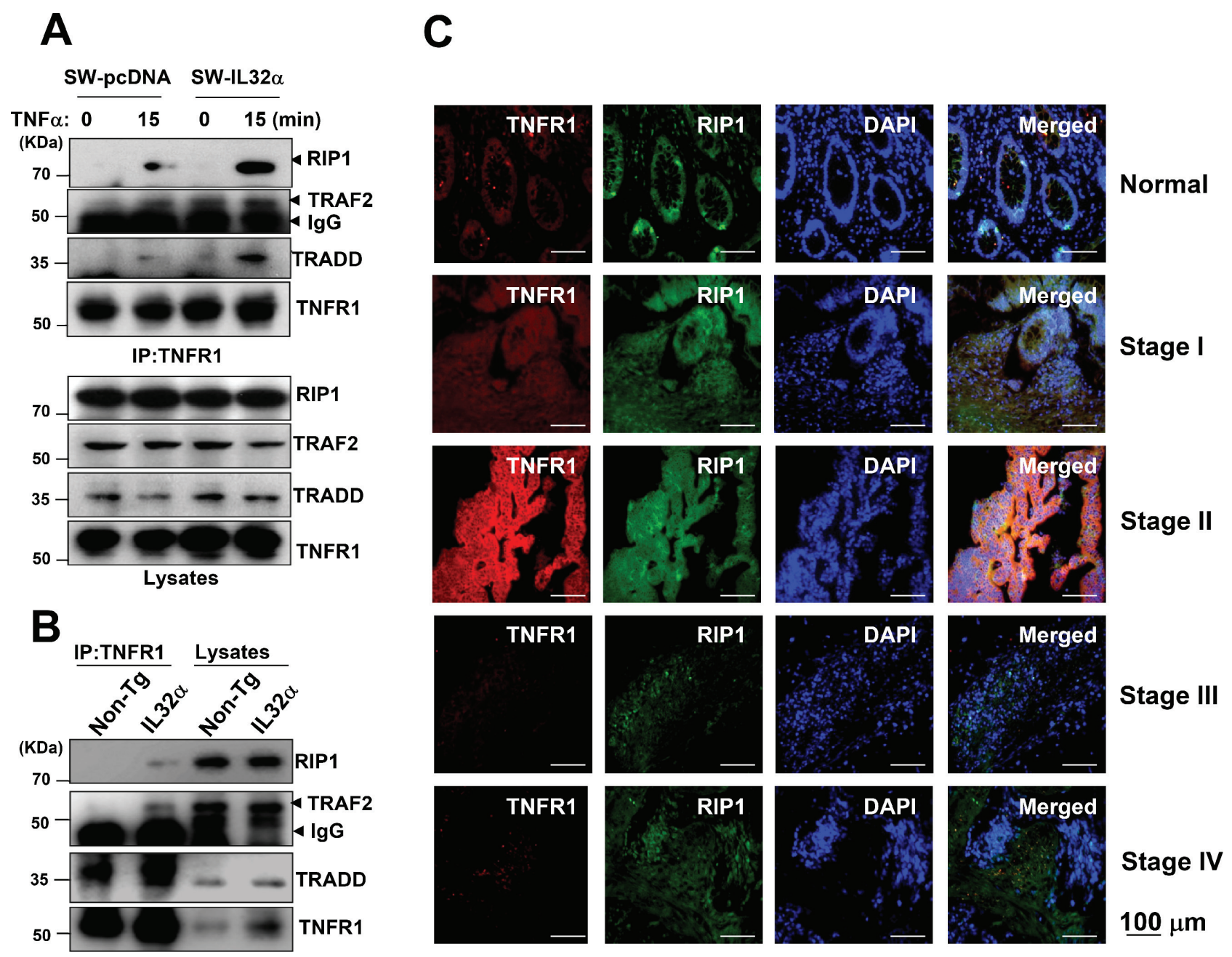

Figure 6: Effect of IL-32 $\alpha$ on TNFR1-adaptor complex in colon cancer development. (A, B) SW-pcDNA cells and SW-IL$32 \alpha$ cells were treated with $30 \mathrm{ng} / \mathrm{ml} \mathrm{TNF} \alpha$ for $15 \mathrm{~min}$. The colon cancer cells (A) and colon tumor tissues (B) from non-Tg and IL-32 $\alpha$ Tg mice were lysated, and then immunoprecipitated with anti-TNFR1 antibody. The immunocomplexes were analyzed by immunoblotting with anti-RIP1, anti-TRAF2, anti-TRADD, anti-TNFR1 antibodies. The total protein expression in cell lysates was identified with the specific antibodies. (C) After human patient tissues were permeabilized, TNFR1 (red) was immunostained with mouse anti-TNFR1 followed by Alex555-conjugated secondary antibodies and RIP1 (green) was immunostained with rabbit anti-RIP1 antibody, followed by Alex488-conjugated secondary antibodies. And then sections were stained with DAPI (blue). The right panels show the merged images of the first, second, and third panels.

our knowledge, the expression pattern suggest that the progression into aggressive cancer stages is due to the loss of anti-cancer effect via suppression of the expression of TNFR1 and IL-32 $\alpha$, and the cell death signaling of TNFR1. Chang and colleague reported that the loss of TNFR1 signaling using TNFR1 knockout mice showed weight loss, severe inflammation, significantly increased vulnerability to carcinogenesis [24]. Similarly, we also demonstrated that the overexpression of IL-32 $\alpha$ upregulated TNFR1 and inhibited CRC development in IL-32 $\alpha$ Tg mice and cell lines. Therefore, it suggests that the regulation of IL- $32 \alpha$ expression is an important factor for CRC development.

In conclusion, we demonstrate the inhibitory effect of IL-32 $\alpha$ on colon tumor provide novel evidence that IL-32 $\alpha$ has a suppressive effect on colon tumor growth through the positive regulation of TNFR1-mediated death signaling during CRC development.

\section{MATERIALS AND METHODS}

\section{Animals}

Non-Tg mice $(n=10)$ and IL-32 $\alpha$ Tg mice $(n=10)$ were used. At 7 weeks of age, all animals except those intended for saline were injected intraperitoneally with $10 \mathrm{mg} / \mathrm{kg}$ of AOM once a week for 6 weeks and sacrificed by $\mathrm{CO}_{2}$ euthanasia at 32 weeks after the start of the AOM injections. 


\section{Plasmids}

To generate transgenic mice that express hIL-32 $\alpha$, concentrated hIL-32 $\alpha \mathrm{cDNA}$ was prepared. The human IL$32 \alpha$ gene (hIL-32 $\alpha$ cDNA) was subcloned into the EcoRI sites of the pCAGGs expression vector from pcDNA3.1 vector. The IL-32 $\alpha$ gene-containing genomic fragment was isolated after restriction enzyme digestion with SalI/ HindIII from the vector, and then separated by a low melting-point agarose from the pCAGGs vector using transverse alternating field-gel electrophoresis.

\section{IL-32 $\alpha$-Tg mice}

The hIL-32 $\alpha$ cDNA fragment was purified and microinjected into the embryos of BDF1 mice. The experimental treatments were carried out according to the guidelines for animal experiments of the Faculty of Disease Animal Model Research Center, Korea Research Institute of Bioscience and Biotechnology (Daejeon, Korea) as well as the guidelines for the welfare and use of animals in cancer research. Diethyl ether was used in animal experiments as a euthanasia agent. After appropriate quantity of ether was poured onto cotton wool and allowed to evaporate and fill the chamber, the animals were placed on the ether soaked cotton wool under a mesh so that the animals do not have direct contact with the liquid chemical (ether). After euthanasia, the animal carcasses and the soaked cotton wool were removed and placed inside the chemical fume hood to allow dissipation of the chemical. The extraction system of the fume hood remained switched on for a further period of 30 minutes after the animal carcasses were handled following standard clinical waste procedures.

\section{Genomic DNA and PCR}

IL-32 $\alpha$ insertion was confirmed by the amplification of genomic DNA isolated from the transgenic mice tails using Super Taq PLUS Pre-mix (RexGene BioTech, Korea) and the following specific primer set: sense, 5-GAA GGT CCT CTC TGA TGA CA-3; and antisense, 5-GAA GAG GGA CAG CTA TGA CTG-3 (nt 22452225). GAPDH was used as an internal control. Genomic DNA samples were extracted from transgenic mice tails using G-spin Total DNA Extraction Kit (iNtRON Biotechnology, Inc., South Korea) and PCR analysis was performed for detection of insertion of IL-32 $\alpha$ in the genome. The following conditions were used for the TaKaRa PCR Thermal Cycler: $94^{\circ} \mathrm{C}$ for $10 \mathrm{~min}$, followed by 35 cycles of $94^{\circ} \mathrm{C}$ for $30 \mathrm{sec}, 63^{\circ} \mathrm{C}$ for $30 \mathrm{sec}$, and $72^{\circ} \mathrm{C}$ for $60 \mathrm{sec}$; with a final step of $72^{\circ} \mathrm{C}$ for $5 \mathrm{~min}$.

\section{Ethics statement}

All animal experiments were approved and carried out according to the Guide for the Care and Use of
Animals [Chungbuk National University Animal Care Committee, Korea (CBNUA-045-0902-01)].

\section{Histological analysis}

\section{Tissue samples treatment}

Tissues were fixed in 10\% buffered formalin, embedded in paraffin blocks, and processed for histological evaluation by routine procedures with $\mathrm{H} \& \mathrm{E}$ staining.

\section{Immunohistochemistry}

Five-micrometer-thick tissue sections and colon cancer patient tissue array with normal colon tissues as control (US Biomax Inc., Rockville, MD) were mounted on poly-glycine-coated slides. The sections were deparaffinized by immersing into xylene solution, rehydrated, subjected to heat-mediated antigen retrieval treatment, washed with distilled water and proceed with immunohistochemical procedure. Endogenous peroxidase activity was quenched by incubation with $1 \%$ hydrogen peroxide solution in methanol for $30 \mathrm{~min}$ and washed with 1X PBS (Sigma, St. Louis, MO) for $5 \mathrm{~min}$. Next, the sections were blocked with 3\% normal horse/goat serum (Vector Laboratories, Burlingame, CA) diluted in 1X PBS for $30 \mathrm{~min}$, incubated overnight with specific antibodies against IL-32 $\alpha$ (1:100, BioLegend, San Diego, CA), PCNA (1:500; Cell signaling Technology, Beverly, MA, TNFR1 (1:400; Santa Cruz Biotechnology, Santa Cruz, CA), and TNFR2 (1:400; Santa Cruz Biotechnology) at $4^{\circ} \mathrm{C}$, and washed 3 times with PBS $1 \mathrm{X}$. The immunological detection was started with incubation in biotinylated goat anti-mouse/rabbit IgG antibody (1:1000 dilution, Vector Laboratories, Burlingame, CA) for $1 \mathrm{hr}$ at room temperature, 3 washings with PBS $1 \mathrm{X}$, continued with avidin-conjugated peroxidase complex (ABC kit, 1:200 dilution, Vector Laboratories, Burlingame, CA) for $30 \mathrm{~min}$ at room temperature 3 washings with PBS 1X. Chromogen development was performed with $0.02 \% 3$, 3'-diaminobenzidine tetrahydrochloride (DAB, Vector Laboratories, Burlingame, CA) and slides counterstained with H\&E. Finally, sections were dehydrated with ethanol, cleared with xylene, and mounted with Permount (Fisher Scientific, Rockford, IL), and evaluated on a light microscopy (Olympus, Tokyo, Japan).

\section{Immunofluorescence}

Sections were incubated overnight with specific antibodies against TNFR1 (1:500; Cell signaling Technology) and RIP1 (1:500; Cell signaling Technology) at $4^{\circ} \mathrm{C}$. After then, the sections were incubated with an anti-rabbit secondary antibody labeled with Alexa-Fluor 488 (1:400 dilution, Invitrogen, Carlsbad, CA) or antimouse secondary antibody labeled with Alexa-Fluor 568 
(1:400 dilution, Invitrogen) for $2 \mathrm{~h}$ at room temperature. Final images were acquired using a confocal laser scanning microscope (TCS SP2, Leica Microsystems AG, Werzlar, Germany).

\section{Cell culture and transfection}

Human SW620 colon cancer cell lines were obtained from the American Type Culture Collection (Manassas, VA). Colon cancer cells were incubated with medium RPMI 1640 containing L-glutamine 1X supplemented with $10 \%$ fetal bovine serum (FBS), 1\% $10000 \mathrm{U} / \mathrm{ml}$ penicillin and $10000 \mu \mathrm{g} / \mathrm{ml}$ streptomycin, at $37^{\circ} \mathrm{C}$ in $5 \% \mathrm{CO} 2$ humidified air. All reagents were purchased from Invitrogen (Carlsbad, CA, USA). To establish constitutive expression systems of IL-32 $\alpha$, cancer cells were transfected with the pcDNA3.1 or pcDNA3.1-IL-32 $\alpha$ vector using the Lipofectamine ${ }^{\mathrm{TM}} 2000$ (Invitrogen). The transfected cells were selected with an antibiotic for neomycin resistance gene, G418 (800 $\mu \mathrm{g} \mathrm{ml}$, Sigma). G418-resistant cells were screened for 3 weeks, and single cell-expanded clones were obtained by serial dilutions. We confirmed the stable expression of IL $32 \alpha$ in SW620 cells using the Western blot. The cells were transiently transfected with TNFR1 siRNA (Santa Cruz Biotechnology) or Control siRNA (Santa Cruz Biotechnology) per well using a mixture of siRNA and WelFect-EX Plus reagent in OPTI-MEM, according to the manufacturer's specification (WelGENE, Seoul, Korea).

\section{TUNEL assay}

DNA fragmentation was examined by terminal deoxynucleotidyl transferase-mediated FITC-dUDP nickend labeling (TUNEL). TUNEL assays were performed using the in situ Cell Death Detection Kit (Roche Diagnostics GmbH, Mannheim, Germany) according to the manufacturer's instructions. Briefly, 25- $\mu \mathrm{m}$ cryosections were fixed with $4 \%$ paraformaldehyde, treated with $0.1 \% \mathrm{NaBH} 4$ and $0.1 \%$ Triton $\mathrm{X}-100$, and incubated for at least $1 \mathrm{~h}$ with a reaction mix containing deoxynucleotidyl transferase and FITC-dUDP (Roche, Reinach, Switzerland). For 4',6'-diamidino-2-phenylindole dihydrochloride (DAPI, Sigma) staining, slides were incubated in the dark at room temperature for $15 \mathrm{~min}$ with mounting medium for fluorescence containing DAPI. The tissues were then observed through a fluorescence microscope (Leica Microsystems AG, Wetzlar, Germany) and the nuclei were visualized by the DAPI staining.

\section{Western blot analysis}

Tissues and cells were homogenized and lysed with lysis buffer (1X PBS, pH 7.4, $10 \mathrm{mM}$ dithiothreitol, $1 \mathrm{mM}$ EDTA, 1\% Triton X-100, and protease inhibitor cocktail) containing $2 \mathrm{mM} \mathrm{Na}_{3} \mathrm{VO}_{4}, 10 \mathrm{mM} \mathrm{Na}_{4} \mathrm{P}_{2} \mathrm{O}_{7}$, and $10 \mathrm{mM} \mathrm{NaF}$ ) for $1 \mathrm{hr}$ on ice. The lysate was centrifuged at
$14,000 \mathrm{rpm}$ for $15 \mathrm{~min}$ at $4^{\circ} \mathrm{C}$. Total protein concentration was determined by the Bradford method (Bio-Rad Laboratories, Berkeley, CA). An equal amount of total protein $(20 \mu \mathrm{g})$ was resolved on an sodium dodecyl sulfate (SDS, Sigma) 10 or $12 \%$ polyacrylamide gel in 1X SDS-PAGE Running buffer (25 mM Tris, $192 \mathrm{mM}$ glycine, $0.1 \%$ SDS) and then transferred to a nitrocellulose membrane (Hybond ECL; Amersham Pharmacia Biotech, Piscataway, NJ). Blots were blocked for $1 \mathrm{hr}$ at room temperature with $5 \%(\mathrm{w} / \mathrm{v})$ non-fat dried milk in Trisbuffered saline Tween-20 (TBST: $10 \mathrm{mM}$ Tris $(\mathrm{pH}$ 8.0) and a $150 \mathrm{mM} \mathrm{NaCl}$ solution containing $0.05 \%$ Tween-20). After washing, membranes were incubated at $4^{\circ} \mathrm{C}$ for overnight with specific primary antibodies against TNFR1, TNFR2, Caspase-8, Caspase-9, Caspase-3, BAX, PCNA, cIAP-1, XIAP, IL-32 $\alpha$, Bid, phospho-JNK, JNK, RIP1, TRAF2, TRADD, phospho-p38, p38, and $\beta$-actin. The blots were then incubated with HRP-conjugated anti-mouse or anti-rabbit antibodies (1:2000, Santa Cruz Biotechnology). Immunoreactive proteins were detected with the enhanced chemiluminescence (ECL, Amersham Pharmacia Biotech) western blotting detection system.

\section{Reactive oxygen species (ROS) generation}

Intracellular accumulation of Reactive oxygen species (ROS) was monitored using OxiSelect ${ }^{\mathrm{TM}}$ Hydrogen Peroxide/Peroxidase Assay Kit (Cell Biolabs, Inc., San Diego, CA). To investigate ROS generation, the tissues and cells were homogenized in 1X Assay Buffer. The lysates were assayed according to manufacturer's procedure.

\section{Tissue microarray}

Tissue microarray incorporating a series of colon cancers with matched normal tissue (US Biomax Inc., Rockville, MD) was used with immunohistochemistry and Immunofluorescence.

\section{MTT assay}

Cell viability was measured by performing an MTT (Sigma) assay to the detect dehydrogenase activity retained in living cells. An aliquot $(50 \mu \mathrm{l})$ of MTT solution $(5 \mathrm{mg} / \mathrm{ml})$ in phosphate-buffered saline was directly added to the cultures, and the cultures were then incubated for $4 \mathrm{~h}$ to allow MTT to metabolize to formazan. Absorbance was measured with an automated spectrophotometric plate reader at a wavelength of $570 \mathrm{~nm}$. Cell viability was expressed as relative percentages in comparison with controls.

\section{JNK activation}

The cells were treated with TNF $\alpha(10 \mathrm{ng} / \mathrm{ml})$ and lysed in lysis buffer (1X PBS, pH 7.4, $10 \mathrm{mM}$ 
dithiothreitol, $1 \mathrm{mM}$ EDTA, 1\% Triton $\mathrm{X}-100$, and protease inhibitor cocktail) containing $2 \mathrm{mM} \mathrm{Na}_{3} \mathrm{VO}_{4}$, $10 \mathrm{mM} \mathrm{Na} \mathrm{P}_{2} \mathrm{O}_{7}$, and $10 \mathrm{mM} \mathrm{NaF}$. Equal amounts of lysate were prepared and immunoblotted with anti-JNK (1:1000; Cell Signaling Technology, Beverly, MA) and anti-phospho-JNK (1:1000; Cell Signaling Technology) antibodies.

\section{Co-immunoprecipitation}

Cells and tissues were gently lysed with lysis buffer for $1 \mathrm{hr}$ on ice and then centrifuged at 14,000 rpm and $4^{\circ} \mathrm{C}$ for $15 \mathrm{~min}$, and the supernatant was collected. The soluble lysates were incubated with anti-TNFR1 antibody (Cell Signaling Technology) at $4^{\circ} \mathrm{C}$ and then with Protein $\mathrm{A} / \mathrm{G}$ bead (Santa Cruz Biotechnology) and washed times. Immune complexes were eluted by boiling for $10 \mathrm{~min}$ at $95^{\circ} \mathrm{C}$ in SDS sample buffer followed by Western blot with anti- RIP1 (1:2000; Cell Signaling Technology), TRAF2(1:1000; Cell Signaling Technology), TRADD (1:1000; Cell Signaling Technology), or TNFR1 (1:2000; Cell Signaling Technology) antibodies.

\section{Statistical analysis}

The data were analyzed using the GraphPad Prism version 4 program (GraphPad Software, Inc., San Diego, CA). Data are presented as mean \pm SD. Statistical significance was performed on the data using one-way analysis of variance (ANOVA) or unpaired Student's $t$-test. A value of $p<0.05$ was considered to be statistically significant.

\section{ACKNOWLEDGMENTS}

This work was supported by a grant from the National Research Foundation of Korea (NRF) funded by the Korean Government (MSIP) (No. MRC, 20080062275).

\section{CONFLICTS OF INTEREST}

The authors declare no conflicts of interest.

\section{REFERENCES}

1. Dahl CA, Schall RP, He HL, Cairns JS. Identification of a novel gene expressed in activated natural killer cells and $\mathrm{T}$ cells. J Immunol. 1992; 148:597-603.

2. Kim SH, Han SY, Azam T, Yoon DY, Dinarello CA. Interleukin-32: a cytokine and inducer of TNFalpha. Immunity. 2005; 22:131-142.

3. Yang MK, Lee SH, Seo HW, Yi KY, Yoo SE, Lee BH, Chung HJ, Won HS, Lee CS, Kwon SH, Choi WS, Shin HS. KR-31761, a novel K+(ATP)-channel opener, exerts cardioprotective effects by opening both mitochondrial $\mathrm{K}+(\mathrm{ATP})$ and Sarcolemmal $\mathrm{K}+(\mathrm{ATP})$ channels in rat models of ischemia/reperfusion-induced heart injury. J Pharmacol Sci. 2009; 109:222-232.

4. Alsaleh G, Sparsa L, Chatelus E, Ehlinger M, Gottenberg JE, Wachsmann D, Sibilia J. Innate immunity triggers IL-32 expression by fibroblast-like synoviocytes in rheumatoid arthritis. Arthritis Res Ther. 2010; 12:R135.

5. Heinhuis B, Netea MG, van den Berg WB, Dinarello CA, Joosten LA. Interleukin-32: a predominantly intracellular proinflammatory mediator that controls cell activation and cell death. Cytokine. 2012; 60:321-327.

6. Haggar FA, Boushey RP. Colorectal cancer epidemiology: incidence, mortality, survival, and risk factors. Clin Colon Rectal Surg. 2009; 22:191-197.

7. Ferlay J, Shin HR, Bray F, Forman D, Mathers C, Parkin DM. Estimates of worldwide burden of cancer in 2008: GLOBOCAN 2008. Int J Cancer. 2010; 127:2893-2917.

8. Shokar NK, Vernon SW, Weller SC. Cancer and colorectal cancer: knowledge, beliefs, and screening preferences of a diverse patient population. Fam Med. 2005; 37:341-347.

9. Bernstein CN, Blanchard JF, Kliewer E, Wajda A. Cancer risk in patients with inflammatory bowel disease: a populationbased study. Cancer. 2001; 91:854-862.

10. Rutter M, Saunders B, Wilkinson K, Rumbles S, Schofield G, Kamm M, Williams C, Price A, Talbot I, Forbes A. Severity of inflammation is a risk factor for colorectal neoplasia in ulcerative colitis. Gastroenterology. 2004; 126:451-459.

11. Shanahan F. Relation between colitis and colon cancer. Lancet. 2001; 357:246-247.

12. Rhodes JM. Unifying hypothesis for inflammatory bowel disease and associated colon cancer: sticking the pieces together with sugar. Lancet. 1996; 347:40-44.

13. Yun HM, Oh JH, Shim JH, Ban JO, Park KR, Kim JH, Lee DH, Kang JW, Park YH, Yu D, Kim Y, Han SB, Yoon DY, Hong JT. Antitumor activity of IL-32beta through the activation of lymphocytes, and the inactivation of NF-kappaB and STAT3 signals. Cell Death Dis. 2013; 4:e640.

14. Oh JH, Cho MC, Kim JH, Lee SY, Kim HJ, Park ES, Ban JO, Kang JW, Lee DH, Shim JH, Han SB, Moon DC, Park YH, Yu DY, Kim JM, Kim SH, et al. IL-32gamma inhibits cancer cell growth through inactivation of NF-kappaB and STAT3 signals. Oncogene. 2011; 30:3345-3359.

15. Cheon S, Lee JH, Park S, Bang SI, Lee WJ, Yoon DY, Yoon SS, Kim T, Min H, Cho BJ, Lee HJ, Lee KW, Jeong SH, Park H, Cho D. Overexpression of IL-32alpha increases natural killer cell-mediated killing through upregulation of Fas and UL16-binding protein 2 (ULBP2) expression in human chronic myeloid leukemia cells. J Biol Chem. 2011; 286:12049-12055.

16. Chen G, Goeddel DV. TNF-R1 signaling: a beautiful pathway. Science. 2002; 296:1634-1635.

17. Wajant H, Pfizenmaier K, Scheurich P. Tumor necrosis factor signaling. Cell Death Differ. 2003; 10:45-65. 
18. Fiers W, Beyaert R, Declercq W, Vandenabeele P. More than one way to die: apoptosis, necrosis and reactive oxygen damage. Oncogene. 1999; 18:7719-7730.

19. Karin M, Lin A. NF-kappaB at the crossroads of life and death. Nat Immunol. 2002; 3:221-227.

20. Ebach DR, Newberry R, Stenson WF. Differential role of tumor necrosis factor receptors in TNBS colitis. Inflamm Bowel Dis. 2005; 11:533-540.

21. Ebach DR, Riehl TE, Stenson WF. Opposing effects of tumor necrosis factor receptor 1 and 2 in sepsis due to cecal ligation and puncture. Shock. 2005; 23:311-318.

22. Locksley RM, Killeen N, Lenardo MJ. The TNF, and TNF receptor superfamilies: integrating mammalian biology. Cell. 2001; 104:487-501.

23. Baker SJ, Reddy EP. Transducers of life and death: TNF receptor superfamily and associated proteins. Oncogene. 1996; 12:1-9.

24. Chang F, Lacey MR, Bouljihad M, Honer Zu Bentrup K, Fortgang IS. Tumor necrosis factor receptor 1 functions as a tumor suppressor. Am J Physiol Gastrointest Liver Physiol. 2012; 302:G195-206.

25. Gupta S. Molecular steps of tumor necrosis factor receptormediated apoptosis. Curr Mol Med. 2001; 1:317-324.

26. De Robertis M, Massi E, Poeta ML, Carotti S, Morini S, Cecchetelli L, Signori E, Fazio VM. The AOM/DSS murine model for the study of colon carcinogenesis: from pathways to diagnosis and therapy studies. J Carcinog. 2011; 10:9.

27. Tanaka T, Kohno H, Suzuki R, Yamada Y, Sugie S, Mori H. A novel inflammation-related mouse colon carcinogenesis model induced by azoxymethane and dextran sodium sulfate. Cancer Sci. 2003; 94:965-973.

28. Huang L, Zhang R, Wu J, Chen J, Grosjean F, Satlin LH, Klein JD, Sands JM, Striker GE, Tan J, Zheng F. Increased susceptibility to acute kidney injury due to endoplasmic reticulum stress in mice lacking tumor necrosis factor-alpha and its receptor 1. Kidney Int. 2011; 79:613-623.

29. Mizoguchi E, Hachiya Y, Kawada M, Nagatani K, Ogawa A, Sugimoto K, Mizoguchi A, Podolsky DK. TNF receptor type I-dependent activation of innate responses to reduce intestinal damage-associated mortality. Gastroenterology. 2008; 134:470-480.

30. Kim YS, Morgan MJ, Choksi S, Liu ZG. TNF-induced activation of the Nox1 NADPH oxidase and its role in the induction of necrotic cell death. Mol Cell. 2007; 26:675-687.
31. Shen HM, Liu ZG. JNK signaling pathway is a key modulator in cell death mediated by reactive oxygen and nitrogen species. Free Radic Biol Med. 2006; 40:928-939.

32. Zhang Y, Chen F. Reactive oxygen species (ROS), troublemakers between nuclear factor-kappaB (NF-kappaB) and c-Jun NH(2)-terminal kinase (JNK). Cancer Res. 2004; 64:1902-1905.

33. Lamb JA, Ventura JJ, Hess P, Flavell RA, Davis RJ. JunD mediates survival signaling by the JNK signal transduction pathway. Mol Cell. 2003; 11:1479-1489.

34. Ventura JJ, Cogswell P, Flavell RA, Baldwin AS Jr, Davis RJ. JNK potentiates TNF-stimulated necrosis by increasing the production of cytotoxic reactive oxygen species. Genes Dev. 2004; 18:2905-2915.

35. Sakon S, Xue X, Takekawa M, Sasazuki T, Okazaki T, Kojima Y, Piao JH, Yagita H, Okumura K, Doi T, Nakano H. NF-kappaB inhibits TNF-induced accumulation of ROS that mediate prolonged MAPK activation and necrotic cell death. EMBO J. 2003; 22:3898-3909.

36. Kamata H, Honda S, Maeda S, Chang L, Hirata H, Karin M. Reactive oxygen species promote TNFalpha-induced death and sustained JNK activation by inhibiting MAP kinase phosphatases. Cell. 2005; 120:649-661.

37. Liu H, Nishitoh H, Ichijo H, Kyriakis JM. Activation of apoptosis signal-regulating kinase 1 (ASK1) by tumor necrosis factor receptor-associated factor 2 requires prior dissociation of the ASK1 inhibitor thioredoxin. Mol Cell Biol. 2000; 20:2198-2208.

38. Tobiume K, Matsuzawa A, Takahashi T, Nishitoh H, Morita K, Takeda K, Minowa O, Miyazono K, Noda T, Ichijo H. ASK1 is required for sustained activations of JNK/p38 MAP kinases and apoptosis. EMBO Rep. 2001; 2:222-228.

39. Chiechi A, Novello C, Magagnoli G, Petricoin EF 3rd, Deng J, Benassi MS, Picci P, Vaisman I, Espina V, Liotta LA. Elevated TNFR1 and serotonin in bone metastasis are correlated with poor survival following bone metastasis diagnosis for both carcinoma and sarcoma primary tumors. Clin Cancer Res. 2013; 19:2473-2485.

40. Yoshimura H, Dhar DK, Nakamoto T, Kotoh T, Takano M, Soma G, Nagasue N. Prognostic significance of tumor necrosis factor receptor in colorectal adenocarcinoma. Anticancer Res. 2003; 23:85-89. 